QUALITY ASSURANCE PLAN FOR THE COLLECTION AND PROCESSING OF SEDIMENT DATA BY THE U.S. GEOLOGICAL SURVEY, WATER RESOURCES DIVISION

by James M. Knott, G. Douglas Glysson, Bernard A. Malo, and LeRoy J. Schroder

U.S. GEOLOGICAL SURVEY

Open-File Report 92-499

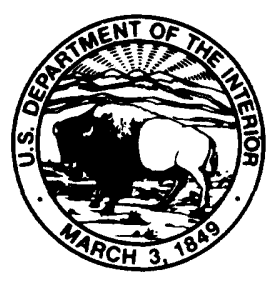




\section{U.S. DEPARTMENT OF THE INTERIOR \\ BRUCE BABBITT, Secretary}

U.S. GEOLOGICAL SURVEY

Dallas L. Peck, Director

The use of trade, product, industry, or firm names is for descriptive purposes only and does not imply endorsement by the U.S. Government.

For additional information write to:

Chief, Branch of Quality Assurance U.S. Geological Survey Box 25046, Mail Stop 401 Federal Center Denver, CO 80225-0046
Copies of this report can be purchased from:

U.S. Geological Survey Books and Open-File Reports Section Box 25425, Mail Stop 517

Federal Center

Denver, CO 80225-0425 


\section{CONTENTS}

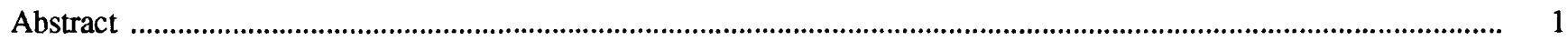

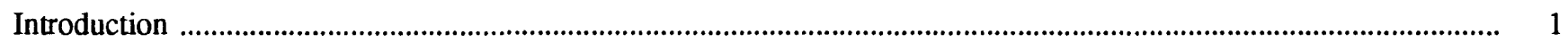

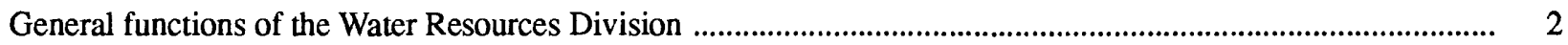

Headquarters organization of the Water Resources Division .................................................................. 2

Field organization of the Water Resources Division .............................................................................. 2

Purpose of quality assurance plan for sediment data collection and processing ................................................... 2

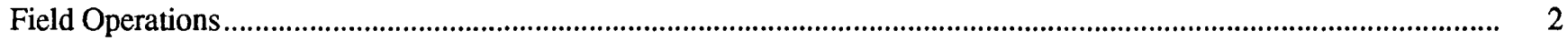

Organization and responsibilities ............................................................................................................. 4

District goals for a sediment station ............................................................................................................... 4

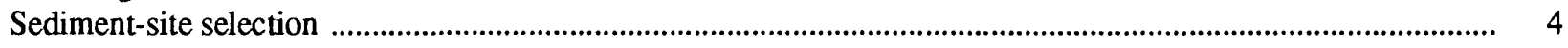

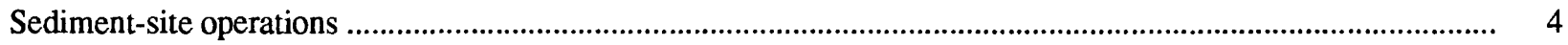

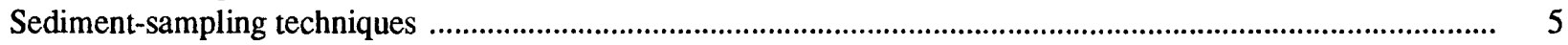

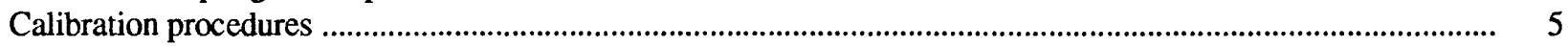

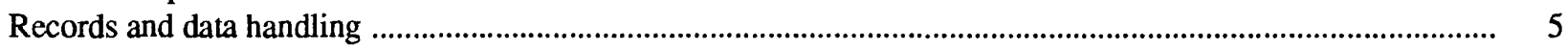

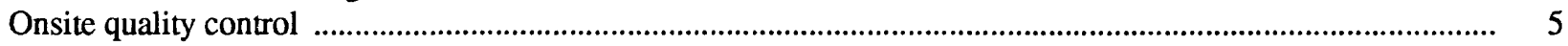

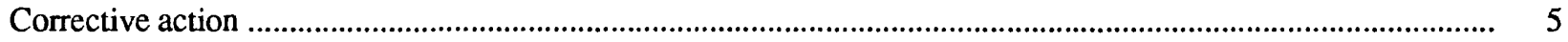

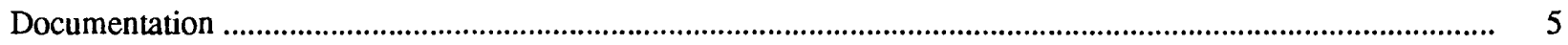

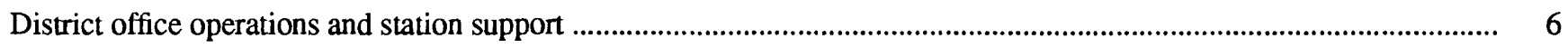

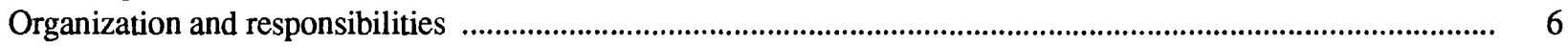

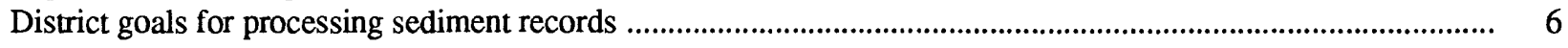

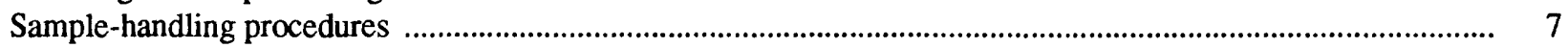

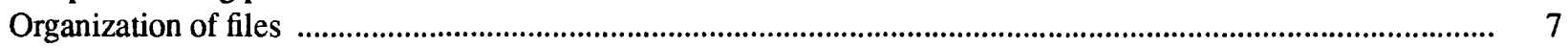

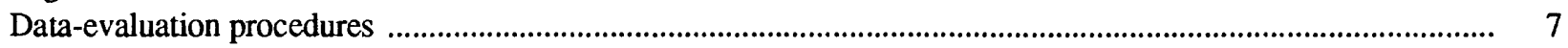

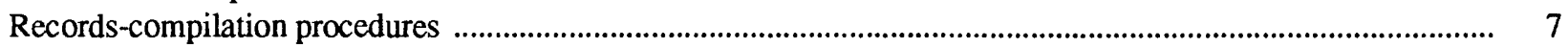

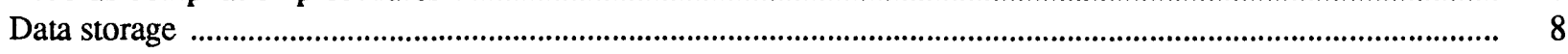

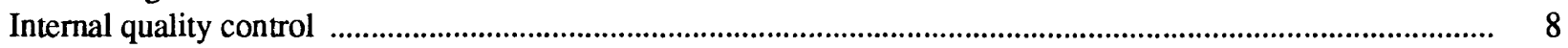

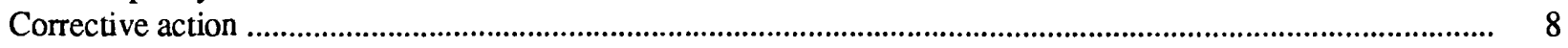

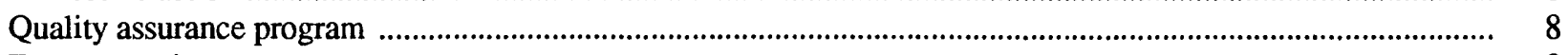

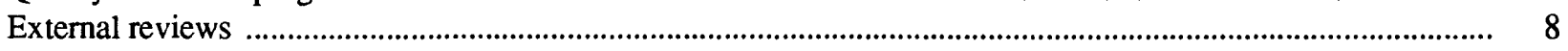

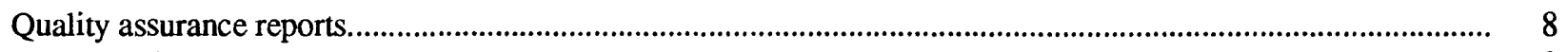

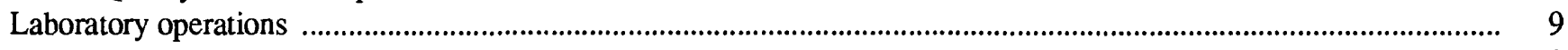

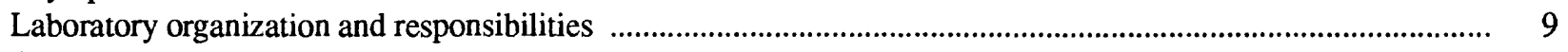

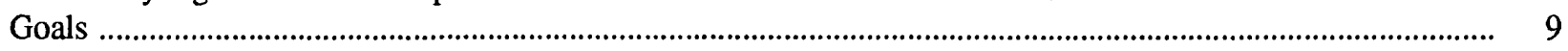

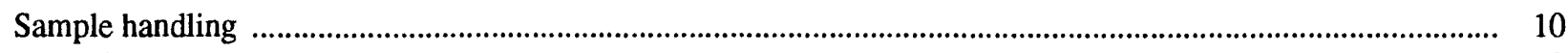

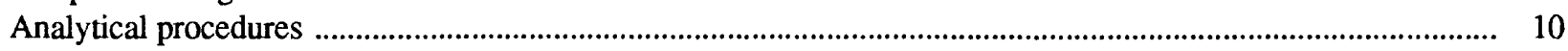

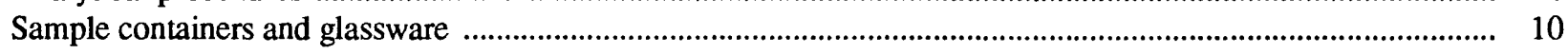

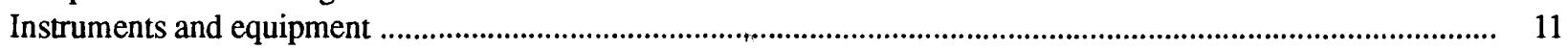

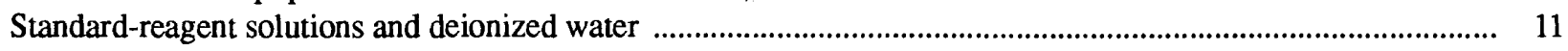

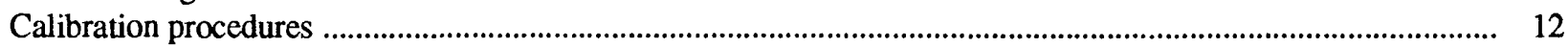

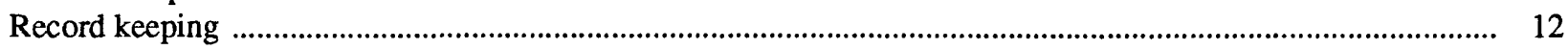

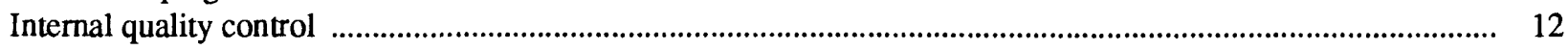

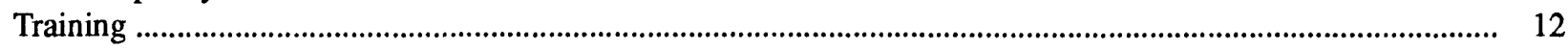

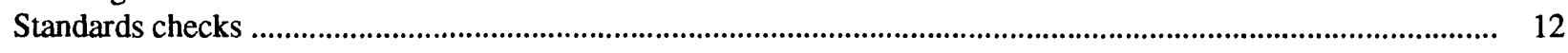

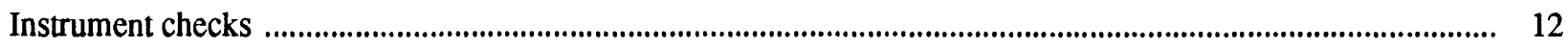




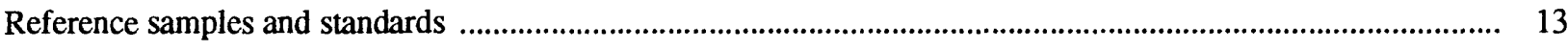

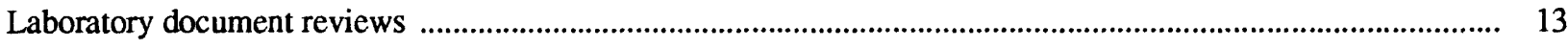

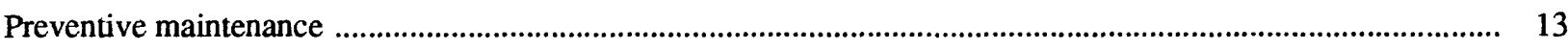

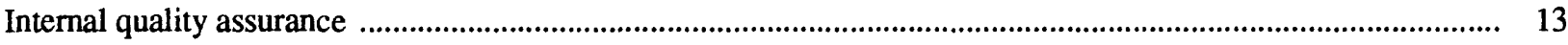

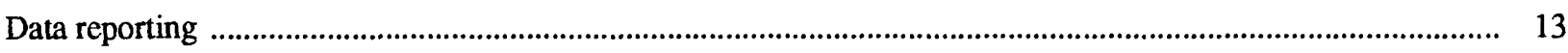

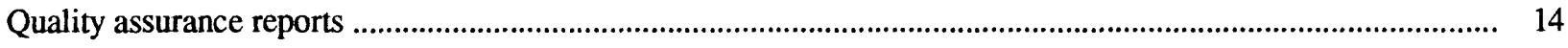

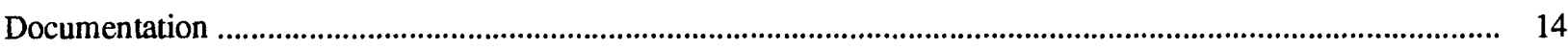

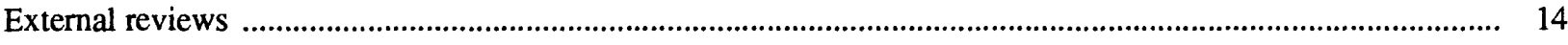

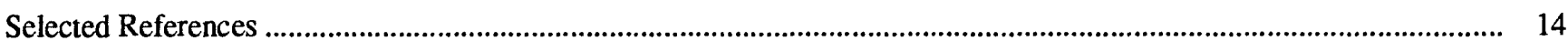

Techniques of Water-Resources Investigations (TWRI) of the U.S. Geological Survey ...................................... 14

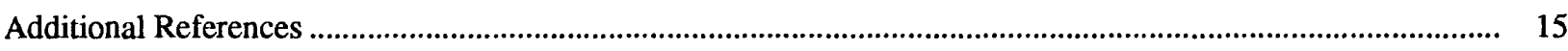

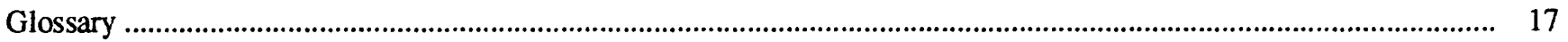

\section{FIGURE}

1. Flow chart showing organization of the Water Resources Division of the U.S. Geological Survey

\section{TABLES}

1. Minimum detection-limit and accuracy criteria for sediment laboratory analyses

2. Standard methods of analysis and the recommended range of particle sizes

for which the methods are applicable

\section{CONVERSION FACTORS AND ABBREVIATED WATER-QUALITY TERMS}

\begin{tabular}{rll}
\hline Multiply & By & To obtain \\
\hline & & \\
gram $(\mathrm{g})$ & 0.03527 & ounce, avoirdupois \\
$\operatorname{liter}(\mathrm{L})$ & 1.057 & quart, liquid \\
$\operatorname{meter}(\mathrm{m})$ & 3.281 & foot \\
milliliter $(\mathrm{mL})$ & 0.03382 & ounce, fluid \\
millimeter $(\mathrm{mm})$ & 0.03937 & inch \\
milligram $(\mathrm{mg})$ & 35.27 & ounce, avoirdupois \\
centimeter $(\mathrm{cm})$ & 0.3937 & inch \\
\end{tabular}

The following terms and abbreviations also are used in the report:

hour (h)

second (s)

liters per second $(\mathrm{L} / \mathrm{s})$

milligrams per liter $(\mathrm{mg} / \mathrm{L})$

grams per liter $(\mathrm{g} / \mathrm{L})$

microsiemens per centimeter $(\mu \mathrm{S} / \mathrm{cm})$ 


\title{
Quality Assurance Plan for the Collection and Processing of Sediment Data by the U.S. Geological Survey, Water Resources Division
}

\author{
By James M. Knott, G. Douglas Glysson, Bernard A. Malo, and LeRoy J. Schroder
}

\section{Abstract}

The quality assurance plan identifies and explains the required quality assurance and suggested quality control practices for obtaining sediment data. The approach is to subdivide the process for obtaining sediment data into three parts: (1) Field, (2) office, and (3) laboratory operations. The report also summarizes recommended goals for each subcategory.

The quality assurance and quality control practices are described by stating the minimum acceptable activities that a district should conduct. For example, the plan describes field calibration of thermometers and standards used to calibrate a thermometer. The plan also proposes corrective actions if the quality control procedures identify a problem.

The plan describes the formal reports prepared by a district that describe the completeness of sediment data and presents an evaluation of data obtained by the quality assurance program. Also described in the plan are the external (non-district) reviews that are needed to examine district sediment operations for conformity with district quality assurance plans and national quality assurance programs.

\section{INTRODUCTION}

The erosion, transport, and deposition of sediment relative to the land surface, streams, reservoirs, and other bodies of water have been a major concern in the United States for hundreds of years. During this period, many sediment problems have adversely affected the use and development of the Nation's land and water resources.

Many human activities, such as silviculture, agriculture, mining, and construction may alter protective vegetal or soil cover and may result in increased erosion. Natural events, such as extremely large rainstorms, wildfires, or volcanic activities, also may contribute to increased erosion rates. Increases in ero- sion are generally accompanied by an increase in the supply of sediment to stream systems which may result in premature filling of lakes and reservoirs, increased flooding of streams, accelerated bank erosion, siltation of fish spawning beds, and hazards to navigation.

Sediment problems can also result from the interruption of the downstream movement of sediment by dams and reservoirs. Consequences of reduced supplies of sediment to a stream system include undercutting of instream structures, excavation and remobilization of contaminants in streambeds, and depletion of sand in beaches.

The needs for sediment information are many and diverse and commonly extend beyond the solution of a specific problem. Individual problems associated with the erosion, transport, or deposition of sediment in a given river basin are intricately related, but each problem occurs in a different part of the basin at a different time. Sediment problems in the lower reaches of a river may occur years, decades, or even centuries after problems are detected in the uplands.

Sediment programs may require sampling and analysis of suspended and bed sediments for extended periods and over wide ranges of hydrologic conditions. It is essential that quality assurance and quality control procedures are developed to ensure that the data obtained are accurate, precise, and representative. Such procedures are equally essential to maintain the accuracy and completeness of sediment records used in research and resource-appraisal investigations.

Quality assurance (QA) provides an opportunity to improve all aspects of the U.S. Geological Survey (USGS), Water Resources Division (WRD) sediment program. Field sites should meet minimum siting criteria. All data obtained at the sites should be obtained by using acceptable equipment and procedures. The WRD district offices and laboratories should strive to operate under sound and well-defined quality assurance programs and established quality control $(\mathrm{QC})$ procedures.

This report provides guidelines for the establishment of $\mathrm{QA} / \mathrm{QC}$ practices that can be applied to the collection and processing of sediment data. The scope of the report primarily relates to the physical aspects of 
sediment and sediment transport. Adherence to the guidelines will ensure high, uniform, and well-defined quality data and provide adequate documentation of individual $\mathrm{QA} / \mathrm{QC}$ programs.

\section{General Functions of the Water Resources Division}

The WRD investigates the occurrence, movement, quantity, quality, distribution, and uses of surface and ground water to develop and disseminate hydrologic information on the Nation's water resources. The collection and dissemination of sediment information is included in many WRD programs and activities. WRD functions are carried out at two levels: headquarters and field. The organizational diagram of these two levels is given in figure 1.

\section{Headquarters Organization of the Water Resources Division}

The headquarters of WRD is located at the U.S. Geological Survey's National Center in Reston, Virginia. Several headquarters groups play unique roles in the effort to obtain sediment information. The Assistant Chief Hydrologist for Program Coordination and Technical Support exercises principal responsibility for: (1) Planning and developing integrated national thrust programs of hydrologic investigations; (2) providing technical advice and support to WRD scientists, including overseeing of quality assurance efforts for scientific and data-collection activities; and (3) overseeing development of new scientific approaches and methodologies for WRD technical programs and formulating the Division's hydrologic training program.

The Office of Surface Water provides leadership in the development of techniques for the collection, analysis, and interpretation of surface-water data by the WRD. In 1985, the leadership responsibility of the Office of Surface Water was broadened to include physical sediment data. The Office of Surface Water provides technical advice to the regional offices and to district offices on matters pertaining to the Nation's surface-water and sediment resources and maintains a system of quality control to assure the technical excellence of field programs and personnel with respect to the collection and processing of surface-water and sediment data. The Branch of Quality Assurance provides QA technical advice to the Office of Surface Water. The Office of Water Data Coordination provides support to the Office of Surface Water through coordination of equipment, sampling, and laboratory procedures development with other federal agencies. The Office of
Water Quality provides water-quality and sedimentrelated technical advice to the Office of Surface Water.

\section{Field Organization of the Water Resources Divislon}

WRD field organization consists of four regions, each headed by a Regional Hydrologist. Each Regional Hydrologist directs operational functions of WRD water-resources programs in their region and coordinates technical and training assistance for district offices. The QA program for sediment data in each region is implemented by the Regional Hydrologist for that region.

Field, office, and laboratory operations are carried out in district offices, each headed by a District Chief. The District Chief is responsible for the planning, direction, and execution of the hydrologic-data collection, laboratory analysis, investigations, and research within the district.

\section{Purpose of Quality Assurance Plan for Sediment Data Collection and Processing}

The objectives of this QA plan are to provide a formal standardization, documentation, and review of policies, procedures, and activities that are used to maintain or improve the quality of sediment information obtained and disseminated by WRD. This document describes various categories of sediment information obtained by WRD; suggested procedures that could be used to obtain, analyze, and process data to ensure its quality; and typical organization and responsibilities of WRD personnel. This plan identifies and explains acceptable QA practices for the selection and operation of field sites, sample handling, operation of laboratories, data and records compilation, and data storage. A list of pertinent references and a glossary of sediment and QA terms is included.

\section{FIELD OPERATIONS}

Field operations include the collection of sediment samples and the measurement of various stream constituents by technical personnel, local observers, or automatic samplers or monitors. The data obtained for a site may include suspended-sediment concentration and particle-size distribution, bedload discharge, bedmaterial size, total load, water discharge, water temperature, stream stage, and field notes. The amount of sediment data obtained for a given site can vary widely depending on program requirements and weather conditions. 


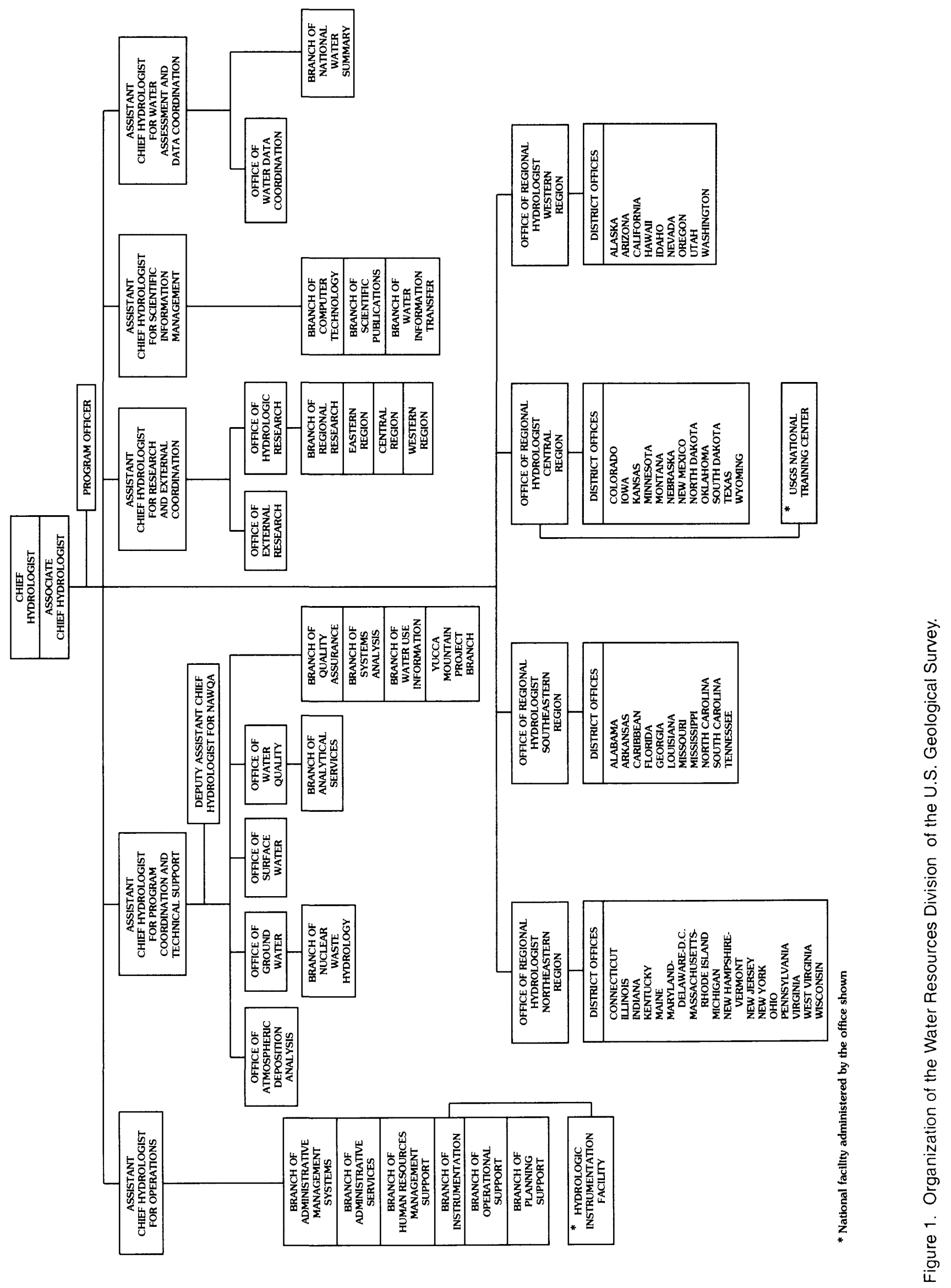




\section{Organization and Responsibilities}

The primary responsibility for collecting, processing, and reporting sediment data rests with the District Chief. The District Chief ensures that technical personnel are adequately trained to carry out their assigned tasks, and that acceptable methods and equipment are used.

One or more persons in a district or regional office should be designated to oversee the quality assurance of sediment data. These persons must be experienced and knowledgeable in proper procedures for obtaining and processing the data.

\section{District Goals for a Sediment Station} tion are:

Typical goals for the operation of a sediment sta-

a. To obtain all data using acceptable field methods and equipment. Guidelines for using acceptable field methods and equipment are described in Guy and Norman (1970), in Edwards and Glysson (1988), in the Annual Book of ASTM Standards (1991), and in internal documents distributed by the WRD and the Offices of Surface Water and Water Quality.

b. To record correct and complete information on all sample containers and field notes.

c. To measure water discharge to an accuracy of \pm 5 percent.

d. To measure water temperature to an accuracy of $\pm 0.5^{\circ}$ Celsius.

e. To measure stream stage to an accuracy of $0.2 \%$ of stage or \pm 0.01 foot ( 0.003 meter $)$, whichever is larger.

\section{Sediment-Site Selection}

The location of sediment-measurement stations should be selected prior to the systematic collection of sediment data following guidelines given in Guy and Norman (1970) and Edwards and Glysson (1988). A description is prepared for each station to document site characteristics, field techniques, calibration procedures, and required laboratory analyses.

The station description should include at least the following information:

a. Stream name and location.

b. Date the site was established. c. Purpose for obtaining the data.

d. Flow and sediment characteristics.

e. Equipment to be used at the site.

f. Sampling techniques, instructions, and frequency.

g. Observer information (if applicable).

\section{Sediment-Site Operations}

The two basic types of sediment stations are periodic and daily. The amount of sediment data obtained for periodic sediment stations usually ranges from 10 to 20 measurements per year. Sediment data obtained for daily sediment stations may include several hundred measurements per year.

Field operations for periodic sediment stations generally include the collection of sediment samples, the measurement of sediment-related constituents, and documentation sufficient to compile a data set of instantaneous values. The data should be representative of the mean value of the constituent in the stream at the time they were obtained.

Sediment data obtained from periodic sediment stations may include samples of suspended-sediment concentration and particle-size distribution, bed material, bedload, and/or total load. Sediment-related data generally include measurements of water discharge, water temperature, stream or particle characteristics, and stream stage. Field notes are used to describe the procedures followed to obtain the data and to report any information that could affect the use, analysis, or interpretation of the data.

Field operations for daily-sediment stations require the collection of a sufficient number of samples to compute daily values of sediment concentration and discharge. The required number and timing of samples usually requires the use of local observers, automatic pumping-type samplers, or sediment monitors.

Samples collected by observers or pumping samplers are commonly obtained at a single sampling vertical or point in the stream and are referred to as box samples. Box samples are obtained on a frequent basis (several hundred times per year) but may or may not be representative of the mean concentration of the stream. Cross-section samples, which are representative of the mean concentration, as well as concurrent box samples, are collected periodically (10 to 20 times per year) by WRD personnel to allow adjustment of values for the samples collected by observers or pumping samplers.

Sediment-related data obtained for daily sediment stations include data similar to those described for 
periodic sediment stations. Field notes are prepared for each visit to a site.

\section{SedIment-Sampling Techniques}

Specific sampling techniques and instructions are given in the station description for each site. The station description is updated to document any substantial changes in sampling techniques or the use of unusual techniques not described in the standard references.

\section{Callbratlon Procedures}

Sediment data obtained from box samples are adjusted to compile a sediment record that is representative of the mean concentration of the stream. Guidelines for obtaining sufficient cross-section and box samples are described in Guy and Norman (1970), Porterfield (1972), and Edwards and Glysson (1988).

Thermometers used in field operations should be calibrated before each field season. Field thermometers are calibrated to \pm 0.5 degree Celsius $\left({ }^{\circ} \mathrm{C}\right)$ at three temperature ranges $\left(0-5^{\circ} \mathrm{C}, 15-25^{\circ} \mathrm{C}\right.$, and $\left.35-45^{\circ} \mathrm{C}\right)$ against a National Institute of Standards and Technology (NIST) certified thermometer.

Thermometers should be visually inspected before each visit to the field site. Observer thermometers are generally checked during site visits. If the water temperature indicated by the observer thermometer varies by more than $0.5^{\circ} \mathrm{C}$ from that of the WRD thermometer, the observer thermometer should be replaced.

\section{Records and Data Handling}

The observer records sample information similar to that shown in Guy and Norman (1970, p. 29) and Edwards and Glysson (1988, p. 52) on the sample container at the sediment station. The observer generally records sample information on a summary form.

During each visit to the field site, WRD personnel should record sample information, observations, equipment maintenance, and other pertinent information on a field-inspection form. If the WRD personnel suspect a potentially dangerous level of a hazardous substance may be present in the sediment sample, a safety protocol should be developed for the transportation and handling of samples.

\section{Onsite Quallty Control}

Quality control procedures used at the sediment station include observer training, equipment and sample inspection, replicate sample collection, and other observations during station visits by WRD personnel.

All new observers should participate in an informal training session at the sediment station. The training session may include a general discussion of introductory hydrologic concepts, specific hands-on instruction in the use of equipment and sampling procedures, basic sampler maintenance, and a schedule for sample collection. The observer's sampling procedures and overall performance should be closely monitored during subsequent visits.

Onsite quality control by observers is accomplished by frequent inspection of sampling equipment and the collection of a specified number of replicate samples. Data can often be improved by providing the observer with the names and telephone numbers of personnel that are available for assistance in remedying problems at the site.

WRD personnel periodically review observer sampling procedures. Observer equipment, samples, and records are inspected at the field site during each visit. WRD personnel should strive to collect sufficient cross-section and box samples to adjust the observer sediment data and periodically collect replicate samples.

Districts should assign a person who is experienced in sediment sampling, such as a section chief or project chief to visit each sediment station at least once per year. This person inspects the site and reviews sampling procedures of both the observer and WRD personnel.

\section{Correctlve Action}

Any problems found during routine visits are to be corrected at the sediment station or are to be brought to the attention of the section or project chief. At each site a control chart (Friedman and Erdmann, 1982, p. 91) is recommended to identify problems at that station. Additional visits to the sites are scheduled if appropriate.

\section{Documentation}

Documentation supporting the field quality assurance activities may include the following: 
a. Current observer sampling instructions are kept at the sediment station.

b. Annual station files are kept at the data-section office. These files include all field-note information obtained for a site in a given water year.

c. A current station description is kept at the district office, the data-section office, and onsite.

d. Appropriate WRD publications and memorandums distributed by the WRD and the Offices of Surface Water and Water Quality are kept at the data-section office and distributed to all WRD field personnel who collect sediment data.

\section{DISTRICT OFFICE OPERATIONS AND STATION SUPPORT} activity:

Office operations include five general areas of

a. Overall support for an observer is generally provided by a designated district office. Each observer is given addresses and phone numbers of offices or WRD personnel from which assistance is available. Direct site support is provided by WRD personnel who supply technical information, supplies, and equipment to the observer. Sediment samples may be transported from the sediment station to a district office, collection site, or laboratory.

b. Quality control of station operations is accomplished by reviewing the information on field forms and compiling discharge and sampling information for station visits. This process helps to ensure that field information is accurate and complete, that sufficient samples are obtained, and that satisfactory procedures and equipment are being used at the field site.

c. Samples should be periodically (not to exceed 90 days) shipped to the laboratory for analysis. Laboratory analyses are evaluated for representativeness and validity. The analyses generally include suspended-sediment concentration and particle-size distribution of suspended sediment, bedload, or bed material.

d. Sediment and streamflow data obtained for sediment stations are processed to compile periodic or daily sediment records. Periodic records are tabulations of instantaneous values of water discharge and temperature, sediment concentration, particle-size distribution, sedi- ment discharge, and other sediment-related constituents. Data compiled for periodic records are representative of the mean value of the constituent for the stream cross section at the time of sample collection. Daily records include instantaneous values, similar to those described for periodic sediment records, and daily values of mean sediment concentration and discharge.

e. Sediment data are entered into computer files as either instantaneous or daily values. The records are stored in the appropriate National data files and are retrieved for publication or to fill data requests.

\section{Organization and Responsibilities}

The organizational structure of office operations varies from district to district. Each district prepares a QA plan that describes the assignment of office and site-support functions to specific persons or hydrologic-data groups. The primary responsibility for the implementation of office operations and station support rests with the District Chief. The District Chief ensures that district personnel are adequately trained to perform their assigned tasks and that acceptable methods of data collection and records compilation are used. One or more persons in the district should be designated to assure the quality of the sediment data and records. These persons should be experienced and knowledgeable in the acceptable procedures for obtaining, processing, and reporting the data.

\section{District Goals for Processing Sediment Records}

The goals for processing each sediment record are:

a. To interact frequently with the observers and laboratory to achieve a satisfactory sediment record for the station.

b. To tabulate correct and complete information on forms and worksheets.

c. To compile sediment records using acceptable and approved methods and procedures. Guidelines for the compilation of sediment records are described in Porterfield (1972, and in internal documents distributed by the WRD and the Offices of Surface Water and Water Quality. 
d. To correctly enter all required sediment data into appropriate computer files.

\section{Sample-Handling Procedures}

Suspended-sediment or total-sediment samples are commonly placed in glass or plastic sample containers and transported from the field site to a consolidation site. The samples are visually inspected for container damage or sample loss at the consolidation site. At the time of inspection, sample deficiencies are recorded on the field-inspection form. The samples are sorted according to station, date, and time and are placed in protective containers for shipment to the laboratory. Sample caps are taped or secured to prevent sample loss. A shipping form is filled out for each shipping container. The shipping form includes a description of each sample in the container. Suspended-sediment and total-sediment samples are stored in a cool, dark place and are shipped to the appropriate laboratory within 1 month of their arrival at the consolidation site. The combined time for sample storage at the field and consolidation sites should not exceed 120 days. Bed-material or bedload samples are transported from the sediment station in bags, cartons, or other containers. Inspection and shipping procedures for these samples are similar to those for suspendedsediment samples.

\section{Organization of Files}

A separate file is maintained for each sediment station for each water year. Each file should include at least the following information:

a. Station description.

b. Field notes and field-inspection forms.

c. Laboratory analyses requests.

d. Work forms with tabulations of sediment and related data.

e. Appropriate charts and compilation forms.

f. Correspondence and other information pertinent to the operation of the sediment station.

g. Checklist of record-processing steps.

h. Station analysis.

\section{Data-Evaluation Procedures}

All sediment data obtained for a sediment station should be evaluated for representativeness and validity. Representativeness means that the samples appear to have been collected in a manner such that the analysis results are representative of the mean value of the constituent for the stream. Validity refers to the probable quality of the sample or analysis data. Data validity may be in doubt if sample identification is missing or ambiguous, the amount of sand in a sample is significantly different from that typical of other samples collected under similar flow conditions, part of the sample is missing, or if analyses of replicate samples indicate conflicting results. Data validity is reinforced when acceptable data-collection and laboratory methods and equipment are used and laboratory quality control is within required limits. Each analysis may be classified as either representative, undefined, or nonrepresentative. Representative and undefined data can be plotted versus corresponding values of water discharge on logarithmic paper. This plot is compared with sedimenttransport relations established for previous data. Data determined or assumed to be outliers are reviewed. Nonrepresentative data and undefined outlier data are excluded from the data set.

Sediment samples obtained at a single vertical in the stream cross section are generally excluded from the data set of representative data. A single-vertical sample may be included in the data set only if it was obtained during high flows where the sediment-transport relation is undefined by previously defined representative data and where the distribution of sediment particles in the cross section is homogeneous. Singlevertical samples used for defining temporal changes in concentration are evaluated by comparing the samples with other samples obtained during similar time periods or flow conditions.

\section{Records-Compilation Procedures}

Sediment data and records are compiled using procedures given in Porterfield (1972). A checklist is used for each site where sediment data are obtained to help ensure that the required steps in compiling the records are completed. Each item on the checklist is initialed to indicate that the work was performed, checked, and reviewed. A station analysis is prepared at the end of each water year to document significant site and operations information. The station analysis describes the constituents determined, documentation of box-sample adjustments, any changes in the sampling program, significant stream and sediment 
characteristics, evaluation of site operations, and other pertinent information. Station analyses for water discharge and sediment records are combined for each site.

\section{Data Storage}

All sediment records compiled by WRD are stored in the national data files. Instantaneous values of sediment and related data are entered in the water quality file. Daily values of water discharge, mean sediment concentration, and sediment discharge are entered in the daily values file. Districts may choose to enter their data into the National Water Information System (NWIS) before transfer to U.S. Geological Survey Water Data and Storage Retrieval Information System (WATSTORE). The daily values are stored in the Automated Data Processing System (ADAPS).

Records entered in the appropriate file are verified at the time of entry by comparing the written records with a primary printout of records stored in the file. Records stored in the computer file are periodically examined during subsequent entry and retrieval until the records are complete for the water year.

\section{Internal Quality Control}

Quality control procedures include examination, checking, and review. Field forms are periodically examined for legibility, completeness, and accuracy. Control charts are maintained to monitor the number of site visits and to ensure that site problems are adequately resolved. Laboratory request forms and correspondence are examined for observations regarding sample condition, sampling deficiencies, and any unusual results. Replicate samples are compared for consistency. Each step of the records compilation procedure is checked by manually processing a percentage of any computer calculated data. If any error is found, all work performed in that step is manually checked. Daily sediment and water-discharge values for periods of rapidly changing concentration and water discharge are plotted on logarithmic paper and are compared with similar values for previous years. Outliers are reviewed for procedural and computational errors. Upon completion of the record, all aspects of field and office operations for each site are reviewed to ensure that district and WRD protocols are being followed. Records stored in computer files are reviewed for reasonableness and completeness.

\section{Corrective Action}

Problems in field operations and sample handling are generally identified by assigned district employees and are promptly corrected by notification or use of alternative procedures. Corrective actions are documented in the individual site files. Errors in record compilation are corrected when identified during checking and review. If any errors are found in the stored records (computer files), all of the stored records for the site are compared with the written records. Corrections are made in the appropriate computer file.

\section{Quality Assurance Program}

Quality assurance activities should be interactive with field, office, and laboratory operations to implement a continuous QA program. Current information is obtained to evaluate the precision, bias, and comparability of the sediment data. The program includes "blind" insertion into the normal sample flow of split samples, spiked samples, blank samples, and reference samples. The frequency of analysis of QA samples is specified in the district QA plan.

\section{External Reviews}

Each district office receives a triennial onsite review by appropriate technical or management personnel from the Office of Surface Water. These reviews examine all aspects of district sediment operations for conformity with the district QA plan and the policies of the National QA program. The reviews include an examination of district sediment laboratories where applicable.

\section{Quality Assurance Reports}

A quality assurance report should be submitted annually by the District Chief to the Regional Hydrologist. This report includes a summary of the type and completeness of district sediment records, results and evaluation of the district QA program, documentation of any problems and corrective actions taken, and any proposed revisions to the district QA plan.

A report for each district review is submitted by the Office of Surface Water to the Regional Hydrologist. This report includes a summary of the type and completeness of sediment records, an evaluation of information obtained in the QA plan, positive and negative aspects associated with the district sediment pro- 
gram, and proposed revisions to district sediment activities.

\section{LABORATORY OPERATIONS}

Matthes and others (1991) and Knott and others (1992) describe examples of quality assurance plans for sediment laboratories. These reports include quality assurance and quality control practices that should be followed in sediment laboratories. The reports also describe laboratory methods for the determination of sediment concentration and particle-size distribution. The methods described in these reports are summarized in this section.

Laboratory operations by WRD and non-WRD laboratories include the analysis of sediment samples and the measurement of sediment-related constituents. Sediment laboratories are maintained by several districts to analyze samples obtained in district sediment programs. Some laboratories operate on a continuous basis and provide analytical services to one or more districts, while other laboratories operate on an intermittent basis.

\section{Laboratory Organization and Responsibilities}

The organization of sediment laboratories varies from district to district. The QA plan for each district describes the analytical functions and organizational structure of laboratory operations administered by the district. The relationship that exists between a district and external laboratories should also be included in the district QA plan.

The primary responsibility for the analysis of sediment samples rests with the chief of the sediment laboratory whose office administers the operation of a specific laboratory. These supervisors should ensure that laboratory personnel are adequately trained to perform their assigned tasks and that acceptable methods of analysis and laboratory procedures are used. The primary responsibility for ensuring that the quality of the laboratory data is acceptable rests with the District Chief of the requesting office.

\section{Goals}

The overall goal of the QA program for sediment laboratories is to produce analytical data whose accuracy and precision are defined. Each laboratory should try to achieve the detection limits given in table 1 .

The goals of the laboratory staff are:

a. To analyze all samples using acceptable methods and equipment. The basic references for acceptable methods of analysis are

Table 1. Minimum detection-limit and accuracy criteria for sediment laboratory analyses

$[\mu \mathrm{S} / \mathrm{cm}$, microsiemens per centimeter at 25 degrees Celsius; >, greater than; $\mathrm{mg} / \mathrm{L}$, milligrams per liter, NTU, nephelometric turbidity units]

\begin{tabular}{lccc}
\hline Measured property & Type of analysis & $\begin{array}{c}\text { Accuracy criterion } \\
\text { (percent) }\end{array}$ & Detection limit \\
\hline Sediment concentration & Filtration $0-50 \mathrm{mg} / \mathrm{L}$ & 15 & $0.5 \mathrm{mg} / \mathrm{L}$ \\
& Filtration $>50 \mathrm{mg} / \mathrm{L}$ & 5 & $0.5 \mathrm{mg} / \mathrm{L}$ \\
Particle-size distribution & Pipet & 5 & $\left({ }^{1}\right)$ \\
& Visual accumulation tube & 5 & $\left({ }^{2}\right)$ \\
Turbidity & Sieve & 5 & $\left({ }^{2}\right)$ \\
Specific conductance & Nephelometric & 10 & $0.1 \mathrm{NTU}$ \\
& Electrometric & & Not applicable \\
& $10-100 \mu \mathrm{S} / \mathrm{cm}$ & 5 & \\
& $>100 \mu \mathrm{S} / \mathrm{cm}$ & 2 & \\
\end{tabular}

(1) Silt-clay concentration must be at least 1,000 milligrams per liter.

(2) Mass of sand must be at least 0.05 gram. 
described in Guy (1969) and in the written communications of the WRD and the Offices of Surface Water and Water Quality, and in Matthes and others (1991) and Knott and others (1992).

b. To enter correct and complete information on all laboratory forms.

c. To analyze all samples within 90 days of arrival at laboratory.

\section{Sample Handling}

Upon receipt at the laboratory, shipping forms and sample labels should be inspected for the indicated presence or suspected presence of harmful substances and for sample condition. USGS Handbook 445-1-H (1989) and Skinner and others (1983) describe safety precautions and procedures for selected hazardous materials.

At the time of inspection, brief comments may be entered on a log-in form to record the visual appearance (and presence of odor) for each sample. Samples in damaged containers should be either discarded or transferred to new containers. All sediment samples must be stored in a cool, dark place to prevent excessive evaporation and growth of organisms.

Samples should be weighed within 1 week of their arrival at the laboratory. A log-in form is commonly used to record required analysis information such as a unique sample-identification number, sample information, and pertinent log-in data.

\section{Analytical Procedures}

The standard methods for analyzing sediment samples are those described in Guy (1969), in the Annual Book of ASTM Standards (1986, a, b), in Matthes and others (1991), and Knott and others (1992), and in internal memorandums of the WRD and Offices of Surface Water and Water Quality. Standard methods of analysis and the recommended range of particle sizes for which the specific methods are used are given in table 2.

Matthes and others (1991) and Knott and others (1992) describe the specific methods, procedures, instruments, and equipment used by an analyst to perform each type of analysis. These reports mandate a QA plan that is updated periodically (at least every 2 years) to account for changes in equipment or laboratory facilities. Changes or modifications to methods of analysis should be made only after notification and approval by the Office of Surface Water.

\section{Sample Containers and Glassware}

Sediment samples are shipped to the laboratory in a variety of glass and polyethylene containers. Each laboratory uses glass or porcelain apparatus for the

Table 2. Standard methods of analysis and the recommended range of particle sizes for which the methods are applicable

[--, not applicable; BW, bottom withdrawal; VA, visual accumulation; $<$, less than; $>$, greater than $]$

\begin{tabular}{lcc}
\hline Determination & Method of analysis & $\begin{array}{c}\text { Recommended particle-size range } \\
\text { (millimeters) }\end{array}$ \\
\hline Concentration & Filtration & $<4.0$ \\
& Evaporation & $<4.0$ \\
Particle-size & Sieve & $0.062-32$ \\
& VA tube & $0.062-2.0$ \\
& Pipet & $0.002-0.062$ \\
Specific conductance & BW tube & $0.002-0.062$ \\
Turbidity & Conductivity meter & -- \\
Specific gravity & Nephelometer & $<0.062$ \\
& Pycnometer & $0.062-2.0$ \\
Specific weight & Displacement & $>2.0$ \\
\hline
\end{tabular}


analysis of sediment samples and stores reagent solutions in specified containers. Procedures for the cleaning, inspection, and handling of sample containers, glassware, and containers for storage of standard solutions should be described in the QA plan for each laboratory.

\section{Instruments and Equipment}

Sediment laboratories use a variety of instruments and equipment to analyze sediment samples and measure sediment-related constituents. Laboratory instruments and equipment generally include the following:

a. Toploading balances are used to determine the weight of sediment samples or sample containers.

b. Analytical balances are used to determine the weight of small quantities of sediment, chemicals, or small glassware.

c. Sieves are used to divide sediment samples into the ranges of particle sizes required for different methods of analysis and for determining the particle-size distribution of samples. Small sieves (3-inch diameter) are generally used for dividing water-sediment mixtures into sand and silt-clay fractions. Large sieves (8 inch diameter) are used for determining the particle-size distribution of bedload or bedmaterial samples. Matthes and others (1991) recommend agitating sieves for 20 minutes by vibrating or shaking devices to pass sediment from the coarser to finer sieves.

d. Equipment used in the Visual-Accumulation (VA) tube analysis includes specially designed glass settling tubes of varying diameters, a recording mechanism that rotates at a constant rate, a carriage that moves vertically and marks the accumulation of sediment in the settling tube, a calibrated thermometer, and a stopwatch.

e. Pipet equipment includes a movable carriage containing the pipet, a constant-temperature water bath, a calibrated thermometer, a stopwatch, and a vacuum source.

f. Equipment used in the Bottom-Withdrawal (BW) tube analysis includes a specially designed $\mathrm{BW}$ glass tube, a calibrated thermometer, and a stopwatch. g. A specific conductance meter capable of readings as low as $1.0 \mu \mathrm{S} / \mathrm{cm}$.

h. A nephelometer is used to determine turbidity. The nephelometer should be capable of measuring turbidities as low as 0.1 nephelometric turbidity unit (NTU) (table 1).

i. Convection-type ovens used to dry the sediment samples are normally operated at temperatures ranging from 80 to $110^{\circ} \mathrm{C}$.

j. Calculators or computers used to calculate, manipulate, display, or store analysis information.

\section{Standard-Reagent Solutions and Deionized Water}

Standard-reagent solutions are used to calibrate laboratory meters. Deionized or distilled water is used to rinse samples into glassware and in the analysis of samples. Several options are available for quality assurance of reagent solutions.

a. Standards for specific conductance meters may be obtained from the National Water Quality Laboratory, from commercial sources, or may be prepared in individual sediment laboratories. Standards obtained from commercial sources or prepared in sediment laboratories will be compared with standards obtained from the National Water Quality Laboratory. Instructions for the preparation and use of standards are given in method I-1780-85, "Specific conductance, electrometric, wheatstone bridge," in Fishman and Friedman (1989).

b. Standards for nephelometers may be obtained from commercial sources or they may be prepared in the laboratory. Standards obtained from commercial sources should be approved by the U.S. Environmental Protection Agency. Instructions for the preparation and use of standards are given in method I-3860-85, "Turbidity, nephelometric," in Fishman and Friedman (1989).

c. Water used in sample rinsing and analysis will be first demineralized by passage through mixed cation-anion exchange resins or by distillation. The specific conductance of each new batch of deionized or distilled water will be determined and recorded in a logbook. The 
specific conductance of the water will not exceed $10 \mu \mathrm{S} / \mathrm{cm}$.

\section{Calibration Procedures}

Calibrated instruments are essential to the achievement of reliable analytical results. Each laboratory maintains the calibration of its instruments by systematic checking with reference standards and by recalibration. The main function of logbooks is to help ensure that instruments are kept in good operating condition.

Each major instrument, such as balances, meters, or drying ovens, will have an individual logbook. An individual logbook may also be used for a work station or for minor instruments such as thermometers or stopwatches. Logbooks typically include information such as instrument specifications, instructions for calibrations, required maintenance schedules, or records of inspection, checking, calibration, and maintenance. The frequency of instrument calibration, maintenance, inspection, and similar instrument evaluation should be documented in the laboratory QA plan.

\section{Record Keeping}

As described previously, logbooks will be maintained for the laboratory instruments. Files will be maintained that will contain shipping and log-in forms, copies of analysis results, and pertinent correspondence for all samples received by the laboratory. Records should be retained for at least 1 year following formal publication of the data.

\section{Internal Quality Control}

Quality control procedures used in sediment laboratories include training, standards and instrument checks, equipment inspection, and laboratory document reviews. Quality control procedures are documented in the laboratory QA plan for each laboratory. Each laboratory should be a part of an interlaboratory program with one or more other WRD laboratories.

\section{Training}

All laboratory personnel participate in training and proficiency test programs for each type of analysis they are expected to make. Proficiency tests should be given to analysts before their initial assignment to per- form a given analysis and at least at yearly intervals thereafter. The laboratory supervisor needs to keep a record of training and proficiency tests for each analyst.

\section{Standards Checks}

Deionized water should be checked at least daily to verify that the specific conductance is less than $10 \mu \mathrm{S} / \mathrm{cm}$. If specific conductance is monitored by automatic devices such as alert lights (Matthes and others, 1991), manual checking can be extended to weekly intervals. Standard-reagent solutions must be reformulated at or before their reliable expiration date.

\section{Instrument Checks}

Recommended practices for checking instruments include:

1. Check toploading and analytical balances with at least two Class $S$ weights (the weights must be in the range of anticipated samples) at the beginning of each work day. Recalibrate the balances if the weighing error exceeds $0.5 \mathrm{~g}$ for the toploading balance or $0.001 \mathrm{~g}$ for the analytical balance. Readjust the balances (both types) to zero after every 10 weighings.

2. Calibrate specific-conductance meters each day or before use with at least two standards representative of anticipated sample conductance. Check the meter with a fresh standard (equivalent conductance) if the meter reading varies by more than plus or minus two percent from any one of the standard values.

3. Check nephelometers each day or before each use with at least two standards within a range of about 0.1 to 100 NTU. Recalibrate the meter if it varies by more than plus or minus five percent from the standard value.

4. Check drying-oven thermometers at least once each month when in use. Compare the oven thermometer with a thermometer of known calibration accuracy $\left( \pm 0.1^{\circ} \mathrm{C}\right)$ at 80 and $110^{\circ} \mathrm{C}$. Replace the oven thermometer if it varies by more than $\pm 2.0^{\circ} \mathrm{C}$ from the calibration thermometer. Other thermometers used in sample analysis are calibrated to $\pm 0.5^{\circ} \mathrm{C}$ at three temperature ranges $\left(0-5^{\circ} \mathrm{C}, 15-25^{\circ} \mathrm{C}\right.$, and $35-45^{\circ} \mathrm{C}$ ) against an NIST-certified thermome- 
ter. Replace these thermometers if they vary by more than $\pm 0.5^{\circ} \mathrm{C}$ from that of the certified thermometer.

5. Check timing devices at least once each month when in use. Compare stopwatches, timers, and clocks with a timing device with an accuracy of 0.001 percent. Replace timing devices that vary by more than \pm 10 seconds per hour from the calibrated device.

6. Visually inspect sieves before each use. Replace any sieves that have torn or excessively stretched screens. Clean any sieves that contain excessive particles imbedded in the screens.

7. Check pipet withdrawal rates before each use. Repair or replace vacuum or pipet apparatus if a withdrawal time cannot be obtained which is within \pm one second of the standard withdrawal time (12-14 seconds).

8. Check calculators and computer algorithms at least once each week or before use. Examples of analyses with known input values and results can be used to verify that the instruments are functioning properly.

\section{Reference Samples and Standards}

Quality control samples (blank, reference, or split samples) are routinely inserted in the normal sample flow to verify correct operation. The minimum number of QC samples ranges from a minimum of one for small batches of samples (1-5) analyzed to one QC sample for each 20 samples (concentration or particle size). At least one reference sample should be inserted for each 100 samples analyzed for concentration. At least one single-point reference standard should be inserted for each 20 measurements of specific conductance or turbidity.

Records of all quality control data should be maintained in the logbook for each work station (analysis) or for each instrument (measurements). The records should be initialed and dated by the analyst.

\section{Laboratory Document Reviews}

The analyst computes, initials, and dates all analysis results. The results need to be reviewed for completeness and reasonableness. The laboratory supervisor manually checks at least 2 percent of the analyses. Laboratory forms, logbooks, and documents are periodically (at least every 60 days) reviewed for legibility, completeness, and accuracy. The chief of the laboratory initials and dates all documents that have been reviewed.

\section{Preventive Maintenance}

A maintenance schedule needs to be established for each instrument. Records of all scheduled and unscheduled maintenance should be kept in an individual logbook for major instruments or work stations. Toploading and analytical balances should be serviced and calibrated by a manufacturer's service representative at least once each year.

\section{Internal Quality Assurance}

Each sediment laboratory should maintain a continuous quality assurance monitoring program for analytical methods. The program includes blind samples inserted into the normal sample flow of split, spiked, blank, and reference samples. QA data should be reported to the requesting district on a quarterly basis. Failure to obtain the expected results on any quality control or quality assurance sample should result in immediate action to identify, correct, and document the problem. The laboratory supervisor is responsible for ensuring the timely solution of identified problems.

\section{Data Reporting}

The reporting of analyses results and operations information by the laboratory is an essential part of the effort to produce high-quality sediment data. In many instances, the prompt reporting of sample deficiencies or unusual analyses results may allow field personnel to obtain additional samples or to quickly correct problems at field sites.

The laboratory chief immediately informs the requesting district office of apparent problems pertinent to sample deficiencies or to field sites. These problems might include:

a. Deficiencies in individual samples.

b. Large differences in results of analyses for replicate samples. 
c. Unusually large percentages of sand in suspended-sediment samples.

d. Excessive growth of organic material in samples.

e. Unusual trends, such as concentration or specific conductance values being nearly constant during periods of changing flow.

Results of analyses are transmitted to the customer in a timely manner.

\section{Quality Assurance Reports}

A QA report should be submitted annually by the laboratory to the District Chief of each requesting district that sends samples to the laboratory. This report should include the results and evaluation of internal QA program analyses and documentation of any problems and corrective actions during the period. A report on the external QA program for the laboratory should be included in the annual QA report submitted by each District Chief to the Regional Hydrologist.

\section{Documentation}

Documents required to support the quality control/quality assurance program of each sediment laboratory consist of basic references, the QA plan, logbooks, and laboratory documents.

a. Matthes and others (1991) and Knott and others (1992) contain specific procedures for sample handling, cleaning of sample containers and glassware, preparation of standards and deionized water, instrument calibration, preparation and analysis of samples, calculations, and internal QC.

b. Individual logbooks should be maintained for each balance, meter, and drying oven in the laboratory. All calibration, inspection, and maintenance data should be recorded in the logbooks.

c. At least one logbook should be maintained for a work station for minor instruments such as thermometers or stopwatches. These logbooks need to contain the required maintenance schedule and all records of inspection, checking, calibration, and maintenance.

d. Laboratory documents include the laboratory QA plan, shipping and log-in records, copies of analysis results, and correspondence relative to data reporting, sample deficiencies, and $\mathrm{QC}$ or QA programs.

\section{External Reviews}

Each sediment laboratory will receive a triennial onsite review by appropriate technical or management personnel from the Office of Surface Water. These reviews will examine all aspects of laboratory operations.

\section{SELECTED REFERENCES}

Acceptable methods for the analysis and reporting of sediment data by the U.S. Geological Survey are given in the Techniques of Water-Resources Investigations series; in internal technical memoranda of the Water Resources Division and the Division's Office of Surface Water and Office of Water Quality, and other publications. Reference is made to the following publications:

\section{TECHNIQUES OF WATER-RESOURCES INVESTIGATIONS (TWRI) OF THE U.S. GEOLOGICAL SURVEY--Numbers indicate book and chapter designation}

TWRI 3-C1 Fluvial sediment concepts, by H.P. Guy, 1970, 55 pages.

TWRI 3-C2 Field methods for measurement of fluvial sediment, by H.P. Guy and V.W. Norman, 1973, 59 pages.

TWRI 3-C3 Computation of fluvial-sediment discharge, by George Porterfield, 1972, 66 pages.

TWRI 5-A1 Methods for determination of organic substances in water and fluvial sediments, by M.J. Fishman and L.C. Friedman, editors, 1985, 709 pages.

TWRI 5-A6 Quality assurance practices for the chemical and biological analyses of water and fluvial sediments, by L.C. Friedman and D.E. Erdmann, 1982, 181 pages.

TWRI 5-C1 Laboratory theory and methods for sediment analysis, by H.P. Guy, 1969, 58 pages. 


\section{Additional References}

American Society for Testing and Materials, 1986, Test methods for turbidity of water (D1889-86): in 1986 Annual Book of ASTM Standards.

1991, Practice for determining suspended-sediment concentration in water samples (D3977-80): in 1991 Annual Book of ASTM Standards.

1991, Guide for sampling fluvial sediments (D4411-

84): in 1991 Annual Book of ASTM Standards.

Bates, Robert L., and Jackson, Julia A., 1987, Glossary of geology: American Geological Institute, Alexandria, Va., $787 \mathrm{p}$.

Edwards, T.K., and Glysson, G.D., 1988, Field methods for measurement of fluvial sediment: U.S. Geological Survey Open-File Report 86-531, 118 p.

Knott, J.M., Sholar, C.J., and Matthes, W.J., 1992, Quality assurance guidelines for the analysis of sediment concentration by U.S. Geological Survey sediment laboratories: U.S. Geological Survey Open-File Report 92$33,30 \mathrm{p}$.

Matthes, W.J., Sholar, C.J., and George, J.R., 1991, Quality assurance plan for the analysis of fluvial sediment by laboratories of the U.S. Geological Survey: U.S. Geological Survey Open-File Report 91-469, 31 p.

Novak, C.E., 1985, Water Resources Division data reports preparation guide: U.S. Geological Survey Water Resources Division Report, 119 p.

Skinner, E.L., Watterson, C.A., Chemerys, J.C., 1983, Laboratory safety handbook: U.S. Geological Survey OpenFile Report 83-131.

U.S. Geological Survey 1975, WATSTORE user's guide:

U.S. Geological Survey Open-File Report 75-426.

1976, Preparation of water-resources data reports: U.S. Geological Survey Report.

1977, National handbook of recommended methods for water-data acquisition: U.S. Geological Survey Report. 1989, Safety and environmental health handbook: U.S.

Geological Survey Report 445-1-H. 


\section{GLOSSARY}

The following definitions are given to provide a more complete description of sediment and quality assurance terms . Most of the definitions were abstracted or adapted from terminology presented in publications such as the National Handbook of Recommended Methods for Water-Data Acquisitions (U.S. Geological Survey, 1977), U.S. Geological Survey TWRI series reports, Matthes and others (1991), and Knott and others (1992).

accuracy.--The extent to which the measured value of a quantity agrees with the accepted value for that quantity.

bedload.--Material moving on or near the stream bed by rolling, sliding, and sometimes making brief excursions into the flow a few diameters above the bed.

bedload discharge.--The quantity of bedload passing a stream cross section in a unit of time.

bed material.--The sediment mixture of which the bed is composed. In alluvial streams, bed-material particles are likely to be moved at any moment or during some future flow condition.

bias.--Systematic error that is manifested as a consistent positive or negative deviation from the known or true value. It differs from random error, which shows no consistent deviation.

blank sample.--A sample of deionized or distilled water that contains zero sediment concentration and whose specific conductance is less than 10 microsiemens per centimeter at $25^{\circ} \mathrm{C}$.

blind sample.--A sample submitted for analysis whose composition is known to the submitter but unknown to the analyst.

box sample.--A sample of the water-sediment mixture of a stream that is obtained at a single point or at a single vertical in the stream.

cross-section sample.--A discharge-weightẹd (velocityweighted) sample of water-sediment mixture collected at one or more verticals in accordance with the technique of depth integration. The discharge of any property of the sample expressible as a concentration can be obtained as the product of the concentration and the water discharge represented by the sample.

deposition.--The mechanical or chemical processes through which sediments accumulate in a resting place.

depth-integration.--A method of sampling a water-sediment mixture so that the contribution to the sample from each point in the vertical is proportional to the stream velocity at that point. This yields a discharge-weighted sample. Ordinarily, depth integration is performed by traversing either a depth- or point-integrating sampler vertically at a constant rate.

erosion.--The wearing away of the land surface by detachment and movement of soil and rock fragments through the action of moving water and other geological agents. nephelometer.--An instrument that measures the amount of light scattered in a suspension.

nonrepresentative sample.--A sample which does not accurately describe of the mean value of the constituent for the stream.

particle-size distribution.--The frequency distribution of the relative amounts of particles in a sample that are within specified size ranges, or a cumulative frequency distribution of the relative amounts of particles coarser or finer than specified sizes. Relative amounts are usually expressed as percentages by mass.

precision.--The degree of similarity among independent measurements of the same quantity, without reference to the known or true value. It often is presented as the inverse of the standard deviation.

pycnometer.--A standard vessel for determining the specific gravity of sediment.

pumping sampler.--A sampler with which the water-sediment mixture is withdrawn through a pipe or hose, the intake of which is placed at a fixed point in a single vertical of the stream cross section.

quality assurance.--All those planned or systematic actions necessary to provide adequate confidence that a product or service will satisfy given requirements for quality.

quality assurance plan (QAP).--A formal document describing the management policies, objectives, principles, organizational authority, responsibilities, accountability, and implementation plan of a group for ensuring quality in its products.

quality control.--The operational techniques and the activities used to fulfill requirements of quality.

reference material.--A material or substance one or more properties of which are sufficiently well established to be used for the assessment of a measurement method or for assigning values to materials.

replicate samples.--A group of samples, collected in a manner such that the samples are thought to be essentially identical in composition. Replicate is the general case for which duplicate is the special case consisting of two samples or measurements.

representative sample.--A sample which accurately describes the mean value of the constituent for the stream.

sediment.--(1) Particles derived from rocks or biological materials that have been transported by a fluid.

(2) solid material (sludges) suspended in or settled from water (for additional information, see Bates and Jackson, 1987). 
sediment concentration $(m g / L)$.--The ratio of the mass of dry sediment in a water-sediment mixture to the volume of the mixture. Sediment concentration is reported in milligrams per liter.

sediment discharge.--The mass or volume of sediment (usually mass) passing a stream cross section in a unit of time. The term may be qualified, for example, as suspended-sediment discharge, bedload discharge, or total-sediment discharge.

sediment sample.--A quantity of water-sediment mixture or deposited sediment that is collected to characterize some property or properties of the sampled medium.

sediment-transport relation.--The relation between water discharge and sediment concentration or sediment discharge. The relation usually is represented as a plot of the values on logarithmic paper.

site.--The locale at which a measurement is made, sample is collected, or other field event takes place; the location of permanent structures installed for an investigation of natural and human-induced water resources phenomena. Synonymous with Station.

specific conductance.--A measure of the ability of a solution to conduct an electric current. Specific conductance is reported in microsiemens per centimeter at a temperature of $25^{\circ} \mathrm{C}$.

specific gravity.--Ratio of the mass of any volume of a substance to the mass of an equal volume of water at $4^{\circ} \mathrm{C}$.

specific weight.--The ratio of the mass of dry sediment in a soil or bed-material sample to the bulk volume of the sample.

spiked sample.--A sample to which known concentrations of specific analytes have been added in such a manner as to minimize the change in the matrix of the original sample.

split sample.--A type of replicate sample in which a sample is split into subsamples contemporaneous in time and space.

standard.--A material established for use as a rule or basis of comparison in measuring or judging capacity, quantity, content, extent, value, or quality.

stream stage.--The water-surface elevation of a stream referenced to a known or arbitrary datum.

stream vertical.--The vertical distance from the surface to the streambed at any observation station in a stream cross section.

suspended sediment.--Sediment that is carried in suspension by the turbulent components of the fluid or by Brownian movement.

suspended-sediment discharge.--The quantity of suspended sediment passing a stream cross section in a unit of time.

total sediment.--The combination of suspended-sediment and bedload material. total sediment discharge.--The total quantity of sediment passing a stream cross section in a unit of time.

transportation (sediment).--The complex processes of moving sediment particles from place to place. The principal transporting agents are flowing water and wind.

turbidity.--A measure of the intensity of light scattered by a sample under defined conditions. Turbidity is reported in nephelometric turbidity units.

undefined sample.--A sample which may or may not be representative of the mean value of the constituent for the stream. Undefined samples include samples collected with insufficient documentation, samples collected using nonstandard procedures, and samples that have been damaged or are incomplete.

unsampled zone.--Part of a stream vertical that is not wholly represented by sediment samples.

water discharge.--The quantity of flow passing a stream cross section in a unit of time. The flow contains water, dissolved solids, and sediment. 